\title{
Determinação do uso e ocupação do solo, destacando as áreas de Reserva Legal e zoneamento urbano da bacia hidrográfica do Ribeirão Candidópolis - MG
}

\author{
Determination of land use and occupation, highlighting the Legal Reserve areas and urban zoning \\ of the Ribeirão Candidópolis - MG watershed \\ Determinación del uso y cobertura del suelo, destacando las áreas de Reserva Legal y zonificación \\ urbana de la cuenca hidrográfica del Ribeirão Candidópolis - MG
}

\author{
Gustavo de Oliveira Dias \\ ORCID: https://orcid.org/0000-0002-2512-8161 \\ Universidade Federal de Itajubá, Brasil \\ E-mail: gustavo2d.gd@gmail.com \\ Elydislei Isabel Alves \\ ORCID: https://orcid.org/0000-0003-4073-7851 \\ Universidade Federal de Itajubá, Brasil \\ E-mail: elydislei.isa@hotmail.com \\ Marina Kelly Andrade Almeida \\ ORCID: https://orcid.org/0000-0002-6602-5142 \\ Universidade Federal de Itajubá, Brasil \\ E-mail: marina.kelly12@gmail.com \\ Victor Henrique Almeida Drummond \\ ORCID: https://orcid.org/0000-0003-4664-0452 \\ Universidade Federal de Itajubá, Brasil \\ E-mail:victoravong@gmail.com \\ James Lacerda Maia \\ ORCID: https://orcid.org/0000-0001-8792-8722 \\ Universidade Federal de Itajubá, Brasil \\ E-mail:jamesmaia@unifei.edu.br \\ Eliane Maria Vieira \\ ORCID: https://orcid.org/0000-0003-1749-6105 \\ Universidade Federal de Itajubá, Brasil \\ E-mail: elianevieira@unifei.edu.br
}

\begin{abstract}
Resumo
A microbacia do Ribeirão Candidópolis é responsável por 55\% do abastecimento urbano de água de Itabira, então a análise das condições ambientais da bacia é de grande importância. Desta forma a determinação do uso e ocupação do solo, destacando aspectos relacionados às áreas de Reserva Legal, bem como a situação do plano de zoneamento urbano e ecológico do município de Itabira (MG) são parâmetros para analisar aspectos de preservação e manejo sustentável na bacia. É de notória importância à utilização de ferramentas de Sistema de Informações Geográficas (SIGs) para análises espaciais no contexto, destacando que as áreas de Reserva Legal estão em aproximadamente $20 \%$ dos imóveis rurais, conforme exigido no código florestal, e essas reservas legais encontram-se em boas condições de preservação e uso. Logo à atual situação da bacia não sofreu grandes alterações, com uma boa preservação das áreas de Reserva Legal. Porém, deve-se reforçar a atenção quanto às áreas de pastagens para que o crescimento dessas áreas não afete as condições naturais da bacia.
\end{abstract}

Palavras-chave: Uso e ocupação do solo; Reserva legal; Manejo sustentável; Ribeirão Candidópolis.

\begin{abstract}
The micro basin of Ribeirão Candidópolis is responsible for 55\% of the urban supply of Itabira, the analysis of the environmental conditions of the basin is of great importance. Thus the determination of land use and occupation, highlighting aspects related to the Legal Reserve areas, as well as the situation of the urban and ecological zoning plan of the municipality of Itabira are parameters to analyze aspects of preservation and sustainable management in the basin. The use of Geographic Information System (GIS) tools for spatial analysis is of notable importance in this context, highlighting that the Legal Reserve areas are in approximately $20 \%$ of the rural properties as required by the Forest Code and that the reserves are in good conditions of preservation and use. Therefore, the current situation of the basin has not undergone major changes, the reserves show a great preservation of the areas of Legal Reserve, bearing in mind
\end{abstract}


that it is necessary to strengthen the attention to the areas of pastures so that their growth does not affect the balance of the basin.

Keywords: Land use and occupation; Legal reserve; Sustainable management; Ribeirão Candidópolis.

\begin{abstract}
Resumen
La microcuenca de Ribeirão Candidópolis es responsable del 55\% del suministro urbano de Itabira, el análisis de las condiciones ambientales de la cuenca es de gran importancia. Así, la determinación del uso y ocupación del suelo, destacando los aspectos relacionados con las áreas de Reserva Legal, así como la situación del plan de zonificación urbana y ecológica del municipio de Itabira son parámetros para analizar aspectos de preservación y gestión sostenible en la cuenca. El uso de herramientas del Sistema de Información Geográfica (SIG) para el análisis espacial es de notable importancia en este contexto, destacando que las áreas de la Reserva Legal son aproximadamente el $20 \%$ de las propiedades rurales, tal y como exige el Código Forestal, y que las reservas están en buenas condiciones de conservación y uso. Por lo tanto, la situación actual de la cuenca no ha sufrido grandes cambios, las reservas muestran una gran preservación de las áreas de Reserva Legal, teniendo en cuenta que se debe reforzar la atención en cuanto a las áreas de pastos para que su crecimiento no afecte el equilibrio de la cuenca.
\end{abstract}

Palabras clave: Uso y ocupación del suelo; Reserva legal; Gestión sostenible; Ribeirão Candidópolis.

\title{
1. Introdução
}

A avaliação, caracterização e quantificação de bacias hidrográficas são aspectos importantes para o planejamento do uso e ocupação do solo, sendo vital para o desenvolvimento geral da sociedade sem prejudicá-la. Diante disso, se faz necessário uma correta utilização de seus recursos naturais.

Tendo em vista a cobertura do solo, o ciclo hidrológico pode ser diretamente afetado por manejos inadequados, uma vez que o uso desordenado do solo na região próximo ao curso d'água acarreta em alterações em seu ciclo. Sendo assim, além de comprometer a qualidade da água utilizada para o abastecimento da população, compromete também as etapas de infiltração e escoamento superficial, portanto, afetando também a quantidade de água na bacia.

No Brasil, a gestão das propriedades rurais vem sendo regida por um conjunto de leis, destacando as que compõem o Código Florestal que determina a limitação de áreas na propriedade para fins de preservação ambiental. No Art $24^{\circ}$ da segunda seção do capítulo dois do Código Florestal de Minas Gerais, Lei nº 20.922/2013, define reserva legal como:

“A área localizada no interior de uma propriedade ou posse rural, delimitada nos termos desta Lei, com a função de assegurar o uso econômico de modo sustentável dos recursos naturais do imóvel rural, auxiliar a conservação e a reabilitação dos processos ecológicos e da biodiversidade, abrigar a fauna silvestre e proteger a flora nativa "(Minas Gerais, 2013).

Com efeito, para a regularização de imóveis rurais é necessário o Cadastro Ambiental Rural - CAR, ele contém informações ambientais da propriedade e é realizado por meio eletrônico para cada estado. No qual é obrigatório que haja uma porcentagem mínima para a reserva legal, sendo $20 \%$ do território total do imóvel (Minas Gerais, 2013). Entretanto, não são todos os imóveis que necessita de constituição de reserva legal segundo o Art $25^{\circ}$ da Lei no 20.922/2013:

“ I - os empreendimentos de abastecimento público de água, tratamento de esgoto, disposição adequada de resíduos sólidos urbanos e aquicultura em tanque-rede;

II - as áreas adquiridas, desapropriadas e objetos de servidão, por detentor de concessão, permissão ou autorização para exploração de potencial de energia, nas quais funcionem empreendimentos de geração de energia elétrica, subestações, linhas de transmissão e de distribuição de energia elétrica” (Minas Gerais, 2013).

A Lei $n^{\circ}$ 12.651/2012 conhecida como Código Florestal do Brasil. Através do Decreto ${ }^{\circ}$ 6.514/2008, são apresentadas sanções administrativas ao não cumprimento das medidas de conservação e proteção da vegetação nativa. Visto que a ausência de cobertura vegetal próximos ao fluxo de água podem gerar danos maiores, devido a vegetação impedir que as partículas carreadas de processos erosivos e de poluentes cheguem ao curso d'água, afetando a qualidade da água. 
Segundo o art $40^{\circ}$ Código Florestal de Minas Gerais (Lei no 20.922/2013), imóveis rurais preexistentes até julho de 2008, que tinham no máximo quatro módulos fiscais, a reserva legal vai ser a área de vegetação nativa da propriedade naquela data, sendo proibido desmatar outras áreas (Minas Gerais, 2013). A medida do módulo fiscal é fixada para cada município, em Itabira, local de estudo, um módulo fiscal corresponde a 20 ha. Ademais, no art $41^{\circ}$ garante que os proprietários de imóveis que realizaram supressão de vegetação dentro dos limites estipulados pela a lei, ficam dispensados de recomposição, compensação ou regeneração (Minas Gerais, 2013).

Este também determina que as Áreas de Preservação Permanente (APP 's) podem fazer parte do cálculo legal da área de reserva. Além disso, imóveis situados em áreas da Amazônia Legal, a reserva deve abranger (80\%) da propriedade se ela for localizada em florestas e $35 \%$ se estabelecida no cerrado, os demais imóveis devem conter obrigatoriamente $20 \%$ de Reservas Legais.

A plena utilização do solo não significa destruir as Áreas de Proteção Permanente (APP 's) no entorno dessas microbacias. Entretanto, usar o solo inadequadamente causará danos significativos ao meio ambiente, e um aumento de áreas conflitivas o uso indevido da terra pode ser justificado pelo aumento da população que gera a necessidade de novas áreas para a construção de moradias e a práticas de atividades (Nascimento, et al., 2020).

A Política Nacional do Meio Ambiente (PNMA) (Lei n 6.938/ 1981), estabelece os instrumentos de gestão os quais podem ser utilizados para uma gestão sustentável das microbacias. Destaca-se o decreto $n^{\circ} 4.297 / 2002$, que regulamenta o Zoneamento Ambiental, o qual possui como objetivo principal o ordenamento urbano, industrial, agrícola de risco climático, agroecológico, socioeconômico-ecológico e o etnozoneamento.

O município de Itabira está localizado no centro sul de Minas Gerais, é muito conhecido como "Cidade do Ferro" por ter sido local de origem da Companhia Vale do Rio Doce, em 1942. Segundo a estimativa do Instituto Brasileiro de Geografia e Estatística (IBGE, 2020) para o ano de 2020 o município possui 120.904 habitantes. Localizado a cerca de $100 \mathrm{~km}$ de Belo Horizonte, o município resguarda a Reserva da Biosfera da Serra do Espinhaço. Reconhecida pela UNESCO, a reserva é uma importante área de proteção do Brasil que passou a integrar uma rede de mais de 400 reservas de biosfera em 100 países.

No município ainda há outras áreas de proteção ambiental regulamentadas a nível municipal. A Lei Municipal de Itabira ( $\left.N^{\circ} 3.547 / 2000\right)$, dispõe que a microbacia do Ribeirão Candidópolis é declarada como área de proteção ambiental, pertencendo a APA Pureza. A lei enquadra também os afluentes e toda a área de drenagem da bacia, além de outros mananciais do município responsáveis pelo abastecimento da população.

Segundo o Serviço Autônomo de Água e Esgoto (SAAE), a bacia hidrográfica do Ribeirão Candidópolis apresenta indicadores de degradação constatados em um estudo realizado em 2014. O estudo revelou que a mesma sofre com a ocupação urbana e o uso irregular do solo rural. Essa é uma região submetida à remoção da cobertura vegetal nativa para estabelecimento de atividades agropecuárias, mineradoras, instalação de indústrias e urbanização (FUNARBE, 2014).

A região tem sofrido uma série de desgastes no solo e comprometendo a qualidade e quantidade da água para abastecimento da população. A intervenção antrópica, está levando a degradação em um trecho do Ribeirão Candidópolis, sendo esta em relação aos seus aspectos físicos, como o desenvolvimento longitudinal, seção transversal, integridade morfológica e regime hidrológico que estão sendo diretamente afetados (Cordeiro et al., 2018).

No relatório final do diagnóstico socioambiental da Bacia do Ribeirão Candidópolis elaborado pela Funarbe (2014) mostra que 81,9\% do esgoto sanitário era destinado de maneira incorreta, 38,4 \% era lançado diretamente em córregos e 43,7\% em fossa negra. Ademais, 15,8\% na rede coletora de esgoto e 2,1\% em fossa séptica (FUNARBE, 2014). Certamente, esse descarte incorreto vai afetar a qualidade da água da bacia. Outrossim, o solo exposto pode afetar a qualidade da água em virtude do carreamento de partículas sólidas para os corpos hídricos, elevando a turbidez, a concentração de sólidos dissolvidos e de nutrientes, o que requer atenção visto que a forma de captação para o abastecimento da cidade nesta bacia se dá por meio de 
captação em mananciais superficiais.

Já em outro estudo mais recente elaborado por Martins (2021), aponta que cerca de 72\% das APP's de nascentes e rios da bacia encontram-se com a devida proteção da mata ciliar, contudo $28 \%$ das APP's não estão de acordo com o exigido pela legislação, este fator pode se dar, devido às ações antrópicas dentre elas empreendimentos, pastagens, infraestruturas urbanas entre outros usos.

Diante da importância desta região para o abastecimento da cidade e em um cenário em que os recursos hídricos destinados ao abastecimento público tem se tornado cada vez mais escassos (tanto em quantidade quanto em qualidade), o presente estudo tem o objetivo analisar as áreas de Reserva Legal, considerando as áreas de APP 's e os limites de reservas das declarações do CAR, frente aos usos e ocupação do solo instalados na bacia, bem como uma análise desta ocupação tendo como norteador do zoneamento urbano, comparando se estas áreas encontram-se preservadas, conforme determinações legais.

\section{Metodologia}

Segundo Pereira et al. (2018), os métodos qualitativos são aqueles nos quais é importante a interpretação por parte do pesquisador com suas opiniões sobre o fenômeno em estudo. $\mathrm{O}$ presente estudo voltou-se principalmente à abordagem qualitativa. Apesar de haver a comparação de dados numéricos, a interpretação dos mesmos é de caráter qualitativo. Ademais, não menos importante, foi necessária a pesquisa explicativa para identificar os fatores que determinam ou contribuem para a ocorrência dos fenômenos.

O trabalho foi desenvolvido utilizando técnicas de Sistemas de Informações Geográficas SIG, utilizando ferramentas como QGIS e Google Earth para confecção dos mapas e comparação com os materiais bibliográficos.

\section{1 Área de estudo}

O Ribeirão Candidópolis se encontra nas coordenadas geográficas 1940’34.62" S e 4312'18.27” O. O manancial que é utilizado para abastecer o Sistema Pureza (ETA-PUREZA) abastece aproximadamente 55\% da população da cidade de Itabira (MG) e está localizado mais próximo do centro de consumo de água da cidade (SAAE, 2021). Assim sendo, as análises da microbacia foram dispostas a partir do uso de Sistemas de Informações Geográficas (SIG), na Figura 1 é apresentado o mapa hidrográfico da microbacia do Ribeirão Candidópolis. 
Figura 1 - Mapa Hidrográfico da microbacia do Ribeirão Candidópolis.

\section{Mapa Hidrográfico da Microbacia do Ribeirão Candidópolis}

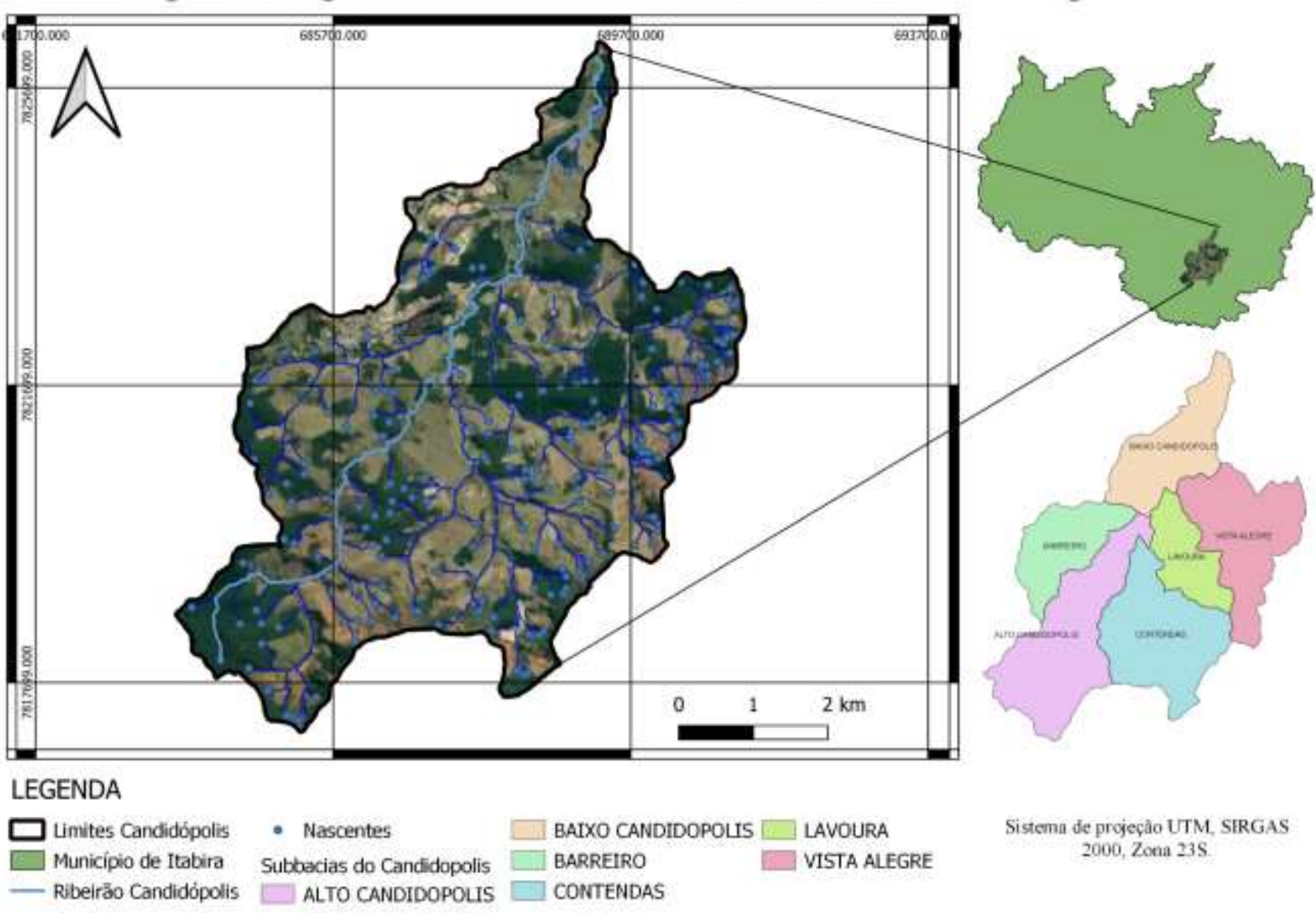

Fonte: Autores.

A microbacia do Ribeirão Candidópolis possui uma área de drenagem de aproximadamente $34 \mathrm{~km}^{2}$, observados na figura 1, os cursos d'água e as nascentes pertencentes à sub-bacia do rio de Peixe, sendo constituída pelos córregos Alto e Baixo Candidópolis, Contendas, Vista Alegre, Barreiro e Lavoura. (SAAE, 2006). Onde, de acordo com Miranda (2014), o Córrego do Cantagalo, sub bacia vizinha, contribui com $23,37 \%$ da vazão do Candidópolis.

A microbacia apresenta características físicas como uma alta densidade de drenagem, com forma alongada, tornando assim menos propensa a possíveis enchentes. Entretanto, embora estas características não indiquem uma propensão para inundações e enchentes, segundo (Cordeiro et al., 2018) o escoamento superficial é aumentado pela redução da capacidade de infiltração do solo, ocasionando uma vazão máxima. Sendo assim, torna-se essencial a preservação da vegetação nativa e a recuperação das áreas degradadas, para que haja a redução do escoamento superficial. A vegetação mais densa em tais áreas evita as cheias e a contaminação das águas superficiais e auxilia na manutenção da vazão do curso d’água nos meses secos do ano.

\subsection{QGIS}

Segundo Santos (2018) o uso de ferramentas de Sistemas de Informações Geográficos (SIG) apresenta grandes características que facilitam a gestão de projetos, permitindo vinculação de imagens e documentos georreferenciados. Assim, deste modo, facilitando trabalhos e análises à distância para aplicações geográficas. 
Para todos os mapas e camadas utilizadas no QGIS adotou-se a projeção UTM, datum SIRGAS 2000, Zona 23 Sul, com o objetivo de padronizar as camadas e utilizando projeções atuais para minimizar erros na localização dos itens presentes nos mapas elaborados, bem como permitir a sobreposição das informações para posterior análise.

\subsection{Zoneamento municipal}

No Art. $139^{\circ}$ do Plano Diretor de Itabira, define algumas diretrizes para o ordenamento territorial do Município de Itabira, dentre elas, no inciso VII considera que o zoneamento deve propiciar a distribuição adequada da população e das atividades socioeconômicas, considerando o equilíbrio entre a ocupação e o uso do solo e a capacidade de suporte do ambiente natural e da infraestrutura disponível (Itabira, 2016).

A partir do Anexo_VIII_Macrozoneamento_A0P, presente no Plano Diretor e disponibilizado pela prefeitura em arquivo PDF, sua conversão foi realizada para formato tiff com o objetivo de manter qualidade para georreferenciar o mapa de macrozoneamento e recortá-lo para área de interesse.

Com à função "Georreferenciador" do QGIS, foram selecionados 10 pontos de acordo com o grid do mapa para georreferenciar em projeção UTM, SIRGAS 2000, zona 23S, após georreferenciado, o raster foi recortado com base na camada de limites do município e da microbacia. Realizado o recorte, o raster foi polinizado para que fosse feito uma melhor delimitação de suas divisões e cálculos de suas respectivas áreas pela "Calculadora de campo".

\subsection{Uso e Ocupação do Solo}

O zoneamento urbano também define o uso e ocupação do solo adequados para as diversas áreas urbanas do município, considerando-se a disponibilidade de infraestrutura, o meio físico, a capacidade de adensamento e o grau de incômodo e de poluição causados ao ambiente urbano (Itabira, 2016).

Para a construção do mapa de Uso e Ocupação do solo na microbacia, foi iniciada uma busca de imagens de satélite que apresentassem boa qualidade, e que a porcentagem de cobertura de nuvens fosse inferior a 10\%, e em bandas que facilitassem a identificação de características específicas no mapa dentro da região da microbacia, para deste modo facilitar a identificação dos itens do mapa de Uso e Ocupação do Solo.

As imagens de satélite foram baixadas no Serviço Geológico dos Estados Unidos (USGS), no qual o satélite selecionado foi o Landsat 8, órbita T130249 obtidas na data 14/12/2020, utilizando as bandas 4,3,2 disponíveis para criar sua composição colorida, representando colorações próximas às naturais. Logo após à extensão do QGIS - "Orfeo ToolBox" foi executada a segmentação das áreas da composição de bandas para pixels semelhantes.

Desta maneira os segmentos foram categorizados no mapa com os seguintes aspectos de uso; vegetação, infraestrutura urbana, lagos, área de pastagem e solo exposto. Nesta etapa, também foram realizadas observações pelo Google Earth para facilitar a identificação do uso presente nas áreas selecionadas como amostras no QGIS.

\subsection{Reserva Legal}

A localização de uma reserva legal segundo o Art. 26 inciso V Código Florestal de Minas Gerais (Lei n²0.922/2013) deverá considerar: o Plano Diretor de Bacia Hidrográfica; o Zoneamento Ecológico-Econômico, a formação de corredores ecológicos, APP, Unidade de Conservação ou outra área legalmente protegida, as áreas de maior importância para a conservação da biodiversidade e as áreas de maior fragilidade ambiental (Minas Gerais ,2013).

Inicialmente foram buscadas informações relacionadas às Reservas Legais declaradas pelos proprietários dos imóveis rurais dentro da área da microbacia do Ribeirão Candidópolis. Estas bases foram extraídas do Sistema Nacional de Cadastro 
Ambiental Rural (SICAR), tais dados são uma autodeclaração realizada pelo proprietário, contendo informações necessárias para o cadastro dos imóveis rurais e Reservas Legais.

Os mapas baixados a partir das consultas públicas disponibilizados pelo SICAR para o município de Itabira foram recortados no Qgis pela ferramenta Recortar, sendo delimitada para dentro da microbacia do Ribeirão Candidópolis. Para as áreas declaradas, aplicou-se à função dissolver para que as camadas se tornem um só vetor com o objetivo de minimizar os erros no cálculo de área realizada pela calculadora de campo.

A comparação para identificar se as áreas de reserva legal estavam sendo preservadas foram feitas com base na utilização da camada do mapa de uso e ocupação. No QGIS é atribuído à ferramenta Interseção, onde a camada de uso será sobreposta com a camada de Reserva Legal, como resultado as áreas que pertencem ao uso do solo e reserva ao mesmo tempo serão destacadas como uma nova camada para análise.

\section{Resultados e Discussão}

\subsection{Zoneamento da microbacia}

A microbacia do Ribeirão Candidópolis apresenta seis macrozonas, conforme apresentado na Figura 2. A maior parte da bacia pertence à Macrozona Rural da Sub-bacia do Córrego Candidópolis com a porção norte pertencente às Macrozonas Urbana e Macrozona Especial Urbana.

Figura 2 - Mapa de Zoneamento da microbacia do Ribeirão Candidópolis.

\section{Mapa de Zoneamento da Microbacia do Ribeirão Candidópolis}

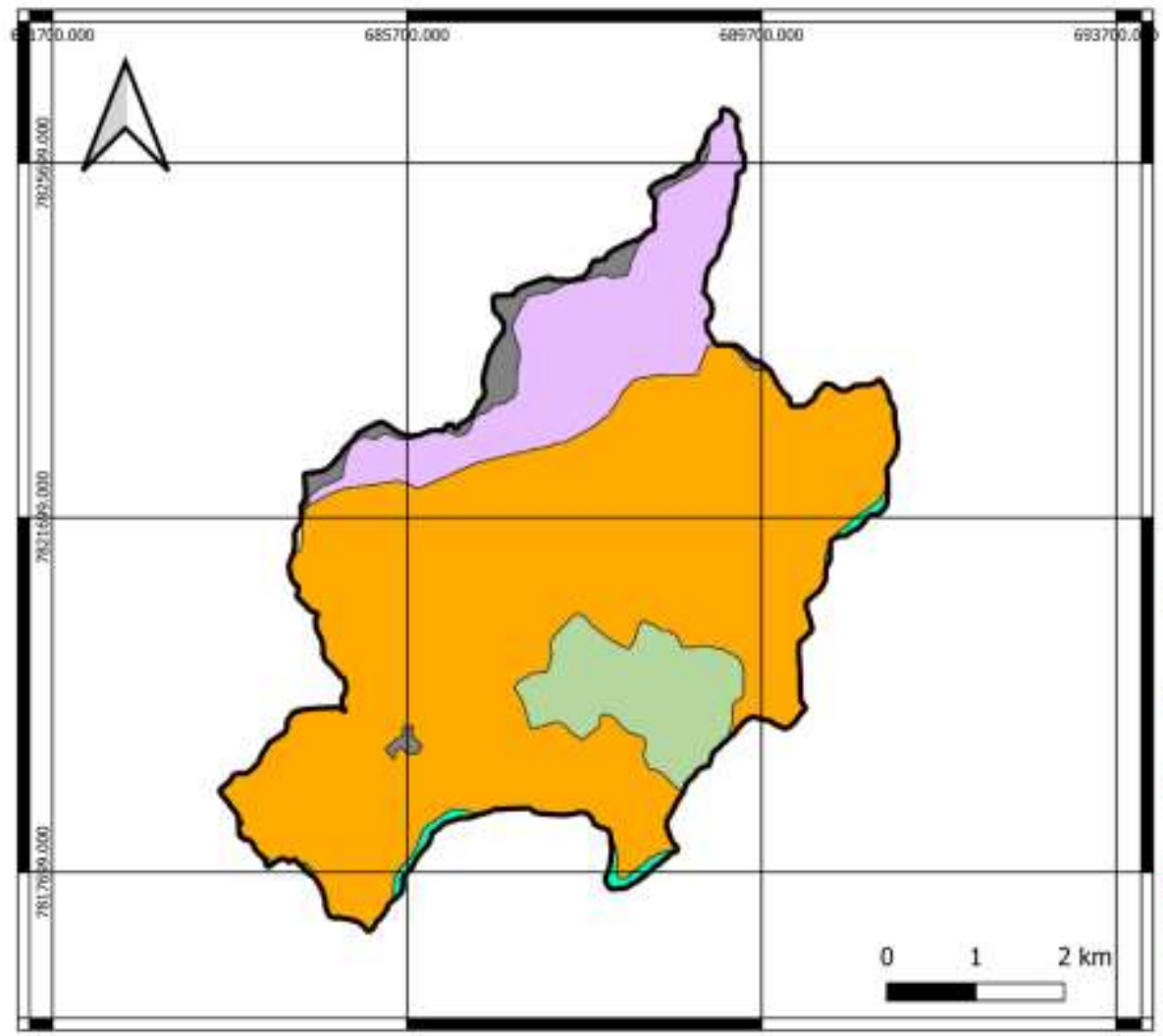

Sistema de projeço UTM, SIRGAS 2000, Zova 23 S

Fonte: Prefeitura de Itabira (Editado).

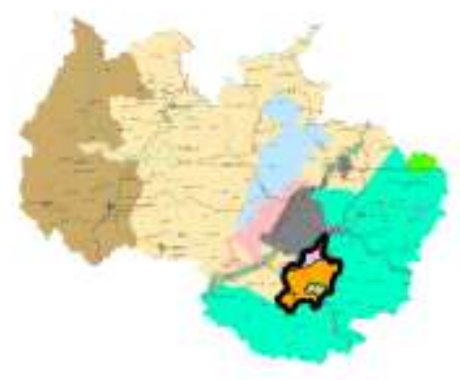

\section{LEGENDA}

Limites da microbada

Macrozona Especial Urbana da Sub-bacia do Córrego Candidópotis

Macrozona Mista de Desenvolvimento Econômico

Macrozona Rural da Sub-bacia do Córrego Candidópolis

Macrozona Rural de Recuperaçäo Ambiental

Macrozona Rural Santo Antỏnio

Macrozonas Urbanas 
Grande parte dos imóveis rurais se encontram situados na Macrozona Rural da Sub-bacia do Córrego Candidópolis e é esta região o foco deste trabalho. Contudo os usos indevidos do solo em todas as Macrozonas podem acarretar alterações nas condições de equilíbrio da microbacia, originadas a partir de ampliações desordenadas no processo de ocupação, mineração e diferentes usos dos solos como agricultura e moradias que podem resultar em diferentes impactos negativos sobre a qualidade ambiental do Ribeirão Candidópolis.

\subsection{Uso e ocupação do solo}

As análises realizadas em relação ao mapa de uso e ocupação, tiveram a base no geoprocessamento empregando a imagem LandSat8 de dezembro de 2020, onde foram identificados e delimitados os usos para à data de 14 de dezembro de 2020, onde os resultados encontram-se apresentados na Figura 3.

Figura 3 - Mapa de uso e ocupação do solo da microbacia do Ribeirão Candidópolis.

\section{Mapa de Uso e Ocupação do Solo da Microbacia do Ribeirão Candidópolis}
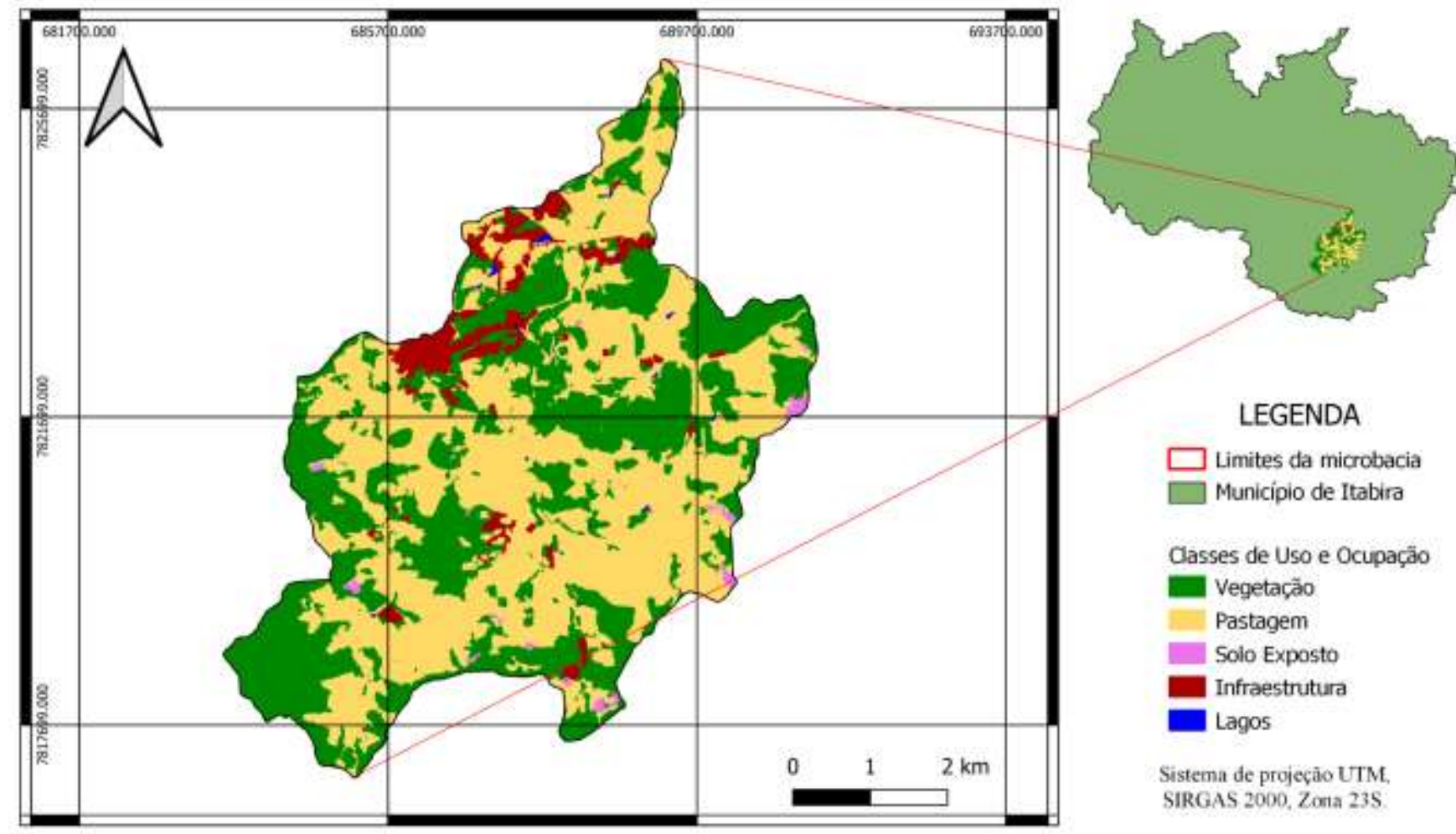

\section{LEGENDA}

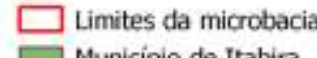

Municipio de Itabira

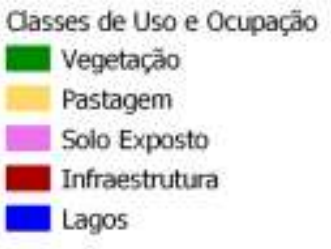

Sistema de projeção UTM, SIRGAS 2000, Zona 235

Fonte: Autores.

Dentre as classes de vegetação são identificadas matas naturais e de reflorestamento, sendo estas as que se apresentam principalmente em áreas de APP's de topos de morro, também é possível notar que grande parte da área está ocupada por pastagens, sendo elas tanto conservadas com um bom estado de manejo, quanto em situação de degradação.

A partir dos cálculos de áreas para os usos executados no QGIS, é possível observar no Quadro 1, a quantificação em hectares para cada tipo de ocupação. 
Research, Society and Development, v. 10, n. 14, e343101422248, 2021

(CC BY 4.0) | ISSN 2525-3409 | DOI: http://dx.doi.org/10.33448/rsd-v10i14.22248

Quadro 1 - Área em hectare (ha) e porcentagem (\%) das classes de uso e cobertura do solo.

\begin{tabular}{|c|c|c|}
\hline Classes & ÁREA (ha) & Porcentagem (\%) \\
\hline Pastagem & 1798,017 & 53,1 \\
\hline Vegetação & 1387,113 & 40,95 \\
\hline Infraestrutura Urbana & 169,595 & 5,0 \\
\hline Solo Exposto & 23,547 & 0,7 \\
\hline Lagos & 9,085 & 0,27 \\
\hline TOTAL & 3387,357 & 100 \\
\hline
\end{tabular}

Fonte: Autores.

Observa-se que pastagem corresponde a aproximadamente 53,1\% da área total da bacia e vegetação (vegetação nativa e reflorestada) 40,95\%, sendo o restante correspondente aos outros usos somados são 5,97 \%.

Comparando com análises realizadas pela FUNARBE (2014), em seu levantamento do meio físico da microbacia, às pastagens representam ainda cerca de $50 \%$ do uso do solo. Tal resultado é confirmado pela consulta realizada ao censo agropecuário realizado pelo IBGE, onde consta a criação de bovinos, nos quais em 2014 eram criados 701 animais por produtores rurais, sendo essa prática uma atividade que deve ocorrer de forma planejada para não ocorrer a danificação do solo.

Após a análise de uso e ocupação do solo, construiu-se o mapa de imóveis rurais e reservas legais da microbacia, conforme Figura 4.

Figura 4 - Mapa de Imóveis Rurais e Reservas Legais da microbacia do Ribeirão Candidópolis.

\section{Mapa de Imóveis Rurais e Reservas Legais da Microbacia do Ribeirão Candidópolis}
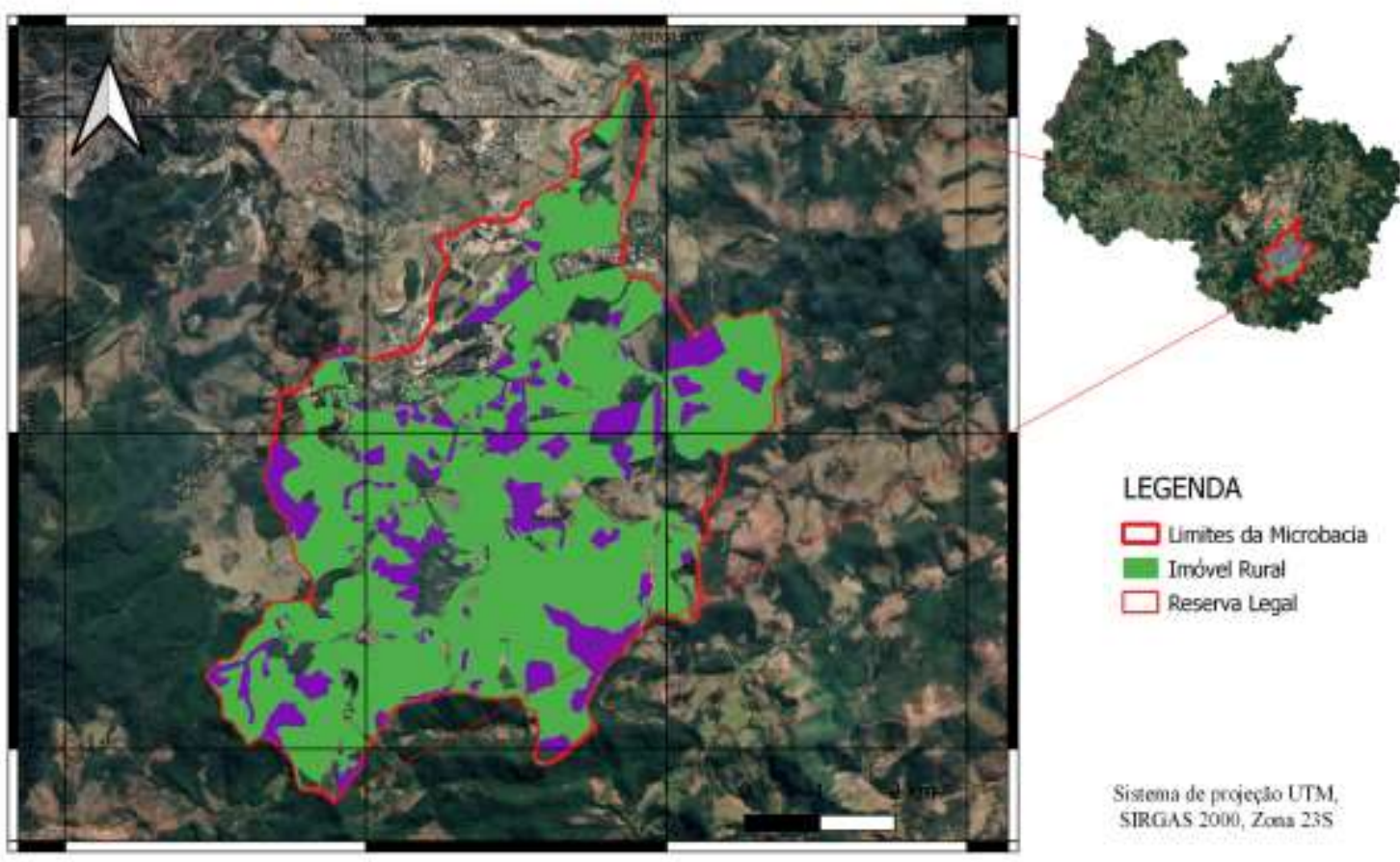

Fonte: Autores. 
É possível observar na figura 4 que o mapa delimita toda a área de imóveis rurais juntamente com os limites das reservas legais da microbacia, segundo declarações do CAR. A microbacia conta com 176 imóveis rurais cadastrados e destes 117 possuem reservas legais declaradas.

A partir disso, foi elaborado o Quadro 2, que quantifica a porcentagem por hectare do imóvel rural e sua reserva legal, segundo declarações do CAR, localizadas na microbacia do Ribeirão Candidópolis.

Quadro 2 - Quantificação das delimitações dos Imóveis Rurais e Reservas Legais da microbacia.

\begin{tabular}{|c|c|c|}
\hline Delimitações & Área (ha) & Porcentagem (\%) \\
\hline Imóvel Rural & 2467,021 & 72,8 \\
\hline Reserva Legal - CAR & 488,35 & 19,795 \\
\hline
\end{tabular}

Fonte: Autores.

É possível observar que 72,8\% da área da microbacia é declarada como áreas de Imóvel Rural, e de acordo com disposições do Código Florestal (Lei 12.651/2012). Logo, a quantificação feita mostra que aproximadamente $20 \%$ da área dos imóveis estão designados como reserva legal, como designado de acordo com as exigências da Lei.

Segundo Vidal (2016), uma má ocupação da sub bacia do Ribeirão Candidópolis pode influenciar na qualidade da água que vai ser captada, tratada e distribuída para o município. Tendo grande impacto, pois a perda das áreas vegetadas para pastagens influenciam no impacto das áreas de recarga do principal manancial de abastecimento público de Itabira. Ademais, as pastagens devem ser utilizadas com cautela evitando processos erosivos, uma vez que os recursos hídricos estão sujeitos a desequilíbrios naturais ou através de ações antrópicas (Vicente et al, 2018).

Logo, para verificar se as áreas de Reservas Legais estão sendo preservadas com cobertura de vegetação, na Figura 5 é possível observar a comparação entre as áreas destinadas à vegetação nos imóveis rurais a partir do mapa de uso e ocupação e as áreas declaradas como reservas legais. 
Figura 5 - Comparação de áreas de Reserva Legal com o uso e ocupação do solo.

\section{Mapa de Interseção entre Uso e ocupação do solo com}

\section{Reservas Legais}

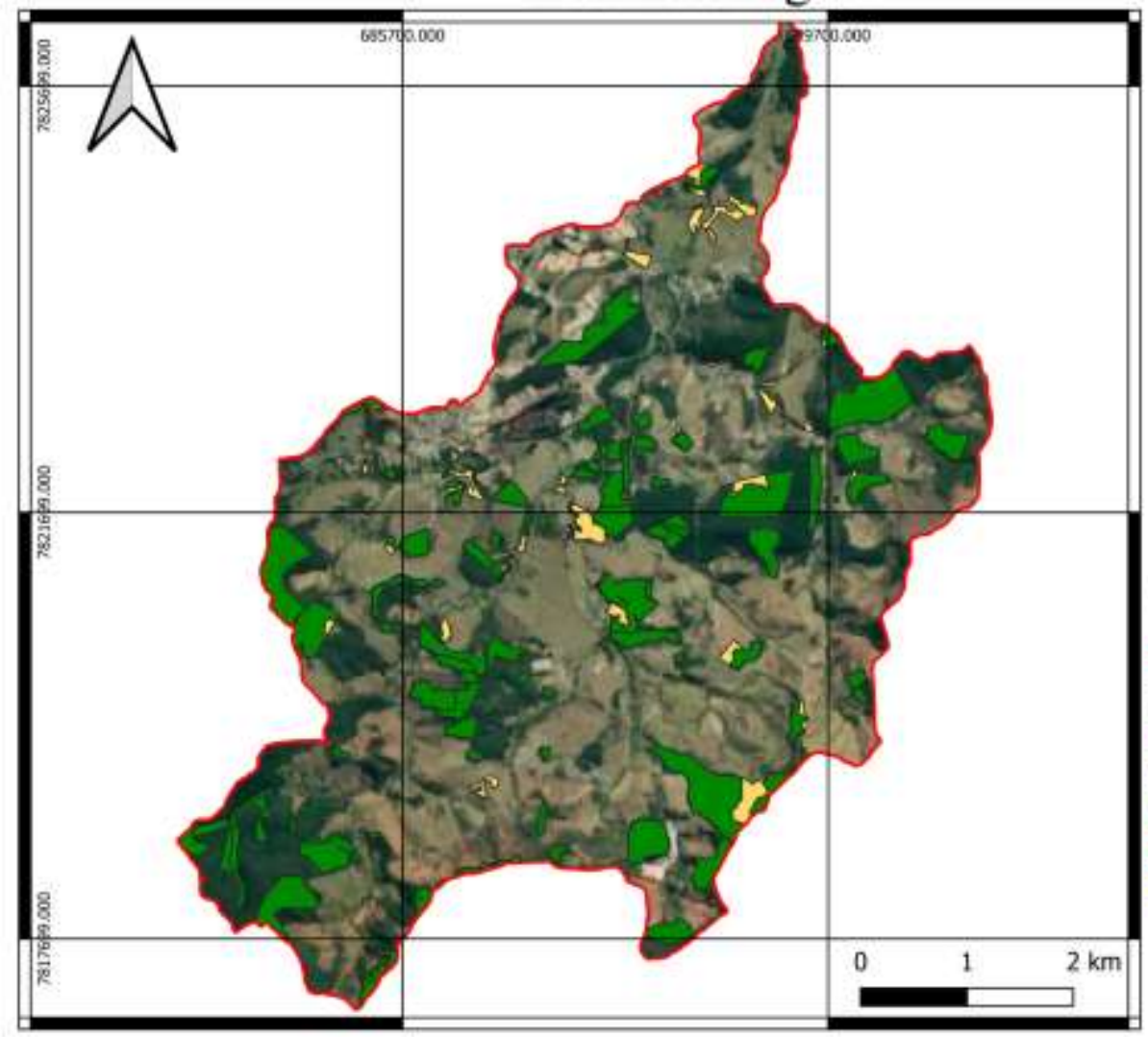

\section{LEGENDA}

$\square$ Limites da microbada

Interseçāo de Reservas Legais e Uso

$\square$ vegetaça

$\square$ Pastagem

$\square$ Solo Exposto

Infraestrutura

Lagos

Fonte: Autores.

É possível observar na figura 5 que a maior parte das áreas de reserva legal se encontram vegetadas e em bons estados de conservação, quantificadas no Quadro 3 temos a proporção dos usos apresentados dentro das reservas legais.

Quadro 3 - Quantificação da área de interseção entre Reservas Legais uso e ocupação.

\begin{tabular}{|c|c|c|}
\hline Classes & ÁREA (ha) & Porcentagem (\%) \\
\hline Vegetação & 422,70 & 86,56 \\
\hline Pastagem & 64,62 & 13,23 \\
\hline Solo Exposto & 0,56 & 0,11 \\
\hline Infraestrutura Urbana & 0,24 & 0,05 \\
\hline Lagos & 0,23 & 0,05 \\
\hline
\end{tabular}

Fonte: Autores.

Enfim, nota-se ao analisar a área da vegetação preservada, sendo equivalente a 86,56 \% das áreas de Reserva Legal que encontram-se com vegetação, sendo 64,62 (13,23\%) são ocupadas áreas de pastagens, sendo o uso que gerou maior impacto nas 
reservas legais de acordo com as análises feitas à partir do uso e ocupação. Destaca-se a importância de um manejo sustentável com o fim de evitar que as áreas de Reservas Legais sejam futuramente tomadas por pastagem.

\section{Considerações Finais}

A partir das análises de preservação das áreas vegetadas na microbacia do ribeirão Candidópolis e o uso e ocupação do solo, foi possível identificar áreas de mata que estão perdendo espaço devido ao aumento das pastagens nas áreas de Reserva Legal. Visto isso, é importante que se mantenha as divisões declaradas no CAR, até para que os proprietários evitem problemas por não estarem de acordo com a legislação.

Como as análises espaciais foram realizadas em datas recentes, a atual situação da bacia não sofreu grandes alterações, mostrando uma grande preservação das áreas de Reserva Legal, mesmo não sendo em sua totalidade. Fatores estes que contribuem com o manejo sustentável da bacia possibilitando uma melhor conservação dos recursos naturais.

Observou-se que as ações antrópicas como construções, empreendimentos e estradas, além das áreas de pastagens tem forte influência na bacia. A expansão dessas ações de maneira inadequada ou sem controle pode contribuir para a deterioração não só dos recursos hídricos do Ribeirão Candidópolis como também da biodiversidade do seu entorno.

Recomenda-se, como sugestão para trabalhos futuros, que seja realizado um estudo do plano de zoneamento urbano e ecológico do município de Itabira, definindo áreas que possam restringir a implantação de novos empreendimentos e o avanço das áreas de pastagens na bacia do Ribeirão Candidópolis.

\section{Agradecimentos}

Agradecemos ao Programa de Educação Tutorial (PET) Engenharia Ambiental - Campus Itabira por todo apoio.

\section{Referências}

Brasil. (1981). Lei n ${ }^{\circ}$ 6.938, de 31 de agosto de 1981. Dispõe sobre a Política Nacional do Meio Ambiente, seus fins e mecanismos de formulação e aplicação, e dá outras providências.

Brasil. (2002) Decreto $n^{\circ}$ 4.297, de 10 de julho de 2002. Regulamenta o art. $9^{\circ}$, inciso II, da Lei no 6.938, de 31 de agosto de 1981, estabelecendo critérios para o Zoneamento Ecológico-Econômico do Brasil - ZEE, e dá outras providências.

Brasil. (2002). Lei Federal $n^{\circ}$ 4.771, de 1965 revogada pela Lei Federal no 12.651, de 2012 e a Resolução CONAMA $n^{o} 303$ de 2002. Dispõe sobre parâmetros, definições e limites de Áreas de Preservação Permanente pelo Conselho Nacional do Meio Ambiente-CONAMA.

Brasil. (2008). Decreto $n^{o} 6.514$, de 22 de julho de 2008. Dispõe sobre as infrações e sanções administrativas ao meio ambiente, estabelece o processo administrativo federal para apuração destas infrações, e dá outras providências.

Brasil. (2012). Lei Federal n ${ }^{\circ}$ 12.651, de 25 de maio de 2012. Dispõe sobre a proteção da vegetação nativa.

Cordeiro, T. S., Abreu, H. A., Silva, P. R., Muller, R. F. M., Alvarenga, D. F., Portilho, D. B., Cordeiro, J. \& Cordeiro, J. L. (2019). Análise morfométrica da Bacia Hidrográfica do Ribeirão Candidópolis, Itabira (MG). Research, Society And Development. 8(1), 0-1. http://dx.doi.org/10.33448/rsd-v8i1.529.

Funarbe.(2014a). Elaboração de diagnósticos socioambientais na Bacia do Ribeirão Candidópolis, Bem Como o Cálculo de Valoração Econômica do Serviço Ambiental a Ser Pago aos Produtores Rurais. Cap II Levantamento de meio físico da bacia do Ribeirão Candidópolis. Fundação Arthur Bernardes (Funarbe). Viçosa - MG, 202 p, v. 1. 2014a.

IBGE. (2020). Cidades e Estados. https://www.ibge.gov.br/cidades-e-estados/mg/itabira.html.

Itabira. (2000). Lei Municipal n 3.547/2000. Dispõe que a microbacia do Ribeirão Candidópolis é declarada como área de proteção ambiental.

Itabira. (2016). Plano Diretor Participativo do Município de Itabira: Prefeitura Municipal de Itabira.

Itabira. (2016). Macrozoneamento Municipal: Prefeitura Municipal de Itabira.

Martins, G. M. F., Marinho, B. T. S., Nascimento, E. B. P., Coutinho, V. O., Dias, G. O., Martins, I. G. M., Maia, J. L. \& Vieira, E. M. (2021). Áreas de preservação permanente como suporte à gestão dos recursos hídricos. Revista Brasileira de Gestão Ambiental e Sustentabilidade, v. 8, n. 19, p. 777-792, 2021. http://dx.doi.org/10.21438/rbgas(2021)081908.

Minas Gerais (2013) Lei 20922/201 de 16 de outubro de 2013 Políticas florestal e de proteção à biodiversidade no Estado. 
Research, Society and Development, v. 10, n. 14, e343101422248, 2021

(CC BY 4.0) | ISSN 2525-3409 | DOI: http://dx.doi.org/10.33448/rsd-v10i14.22248

Minas Gerais (2013) Lei 20922/201 de 16 de outubro de 2013. Art 25º delibera à constituição de reserva legal . Políticas florestais e de proteção à biodiversidade no Estado.

Minas Gerais (2013) Lei 20922/201 de 16 de outubro de 2013. Art 25 rt 41 define que à supressão de vegetação nativa deve respeitar os percentuais de Reserva Legal. Políticas florestais e de proteção à biodiversidade no Estado.

Miranda, G. O., Maia, J. L., Guimarães, J.C.C. \& Luiz, L. M. (2014). contribuição quantitativa dos recursos hídricos do córrego Cantagalo para o Ribeirão Candidópolis, Itabira - MG. Enciclopédia Biosfera, Centro Científico Conhecer - Goiânia, v.10, n.18; p. 2014. http://www.conhecer.org.br/enciclop/2014a/AGRARIAS/Contribuicao\%20Quantitativa.pdf.

Nascimento, T. V., Fernandes, L. L., Gomes, A. B. B., Castro, L. R. C. \& Lira, B. R. P. (2020) Caracterização socioeconômica e ambiental da bacia hidrográfica do Igarapé da Prata, Capitão Poço, Estado do Pará, Brasil. Revista Research, Society and Development,v. 9, n.11 p 3, 2020. http://dx.doi.org/10.33448/rsdv9i11.8714.

Santos, À. L, F., \& Barbosa, F., P. (2018). Sistema de Informações Geográficas (SIG) - A importância do uso da ferramenta SIG para projetos de gasodutos. Revista Científica Multidisciplinar Núcleo do Conhecimento. Ano 03, Ed. 08, Vol. 13, pp.88-101, Agosto de 2018. ISSN:2448-0959.

Vicente, I, T., \& Cordeiro, J. (2018). Diagnóstico de degradação do Ribeirão Candidópolis, Itabira (MG): uma contribuição para propostas de restauração. Research, Society And Development. http://dx.doi.org/10.17648/rsd-v7i2.174.

Serviço Autônomo de Água e Esgoto. SAAE. (2006). Projeto mãe d'água.

Serviço Autônomo de Água e Esgoto. SAAE. (2021).Origem da água. http://www.saaeitabira.com.br/index.php/en/agua-esgoto/origem-agua.

Sistema Nacional de Cadastro Ambiental Rural - SICAR (2021). https://www.car.gov.br/publico/imoveis/index.

Vidal, J. M. C. (2019). Análise do uso e ocupação do solo nas áreas de Proteção Ambiental - APAs Piracicaba e pureza em Itabira-MG. Bambuí, 2019. 88p V648a. https://repositorio.bambui.ifmg.edu.br/index.php/mpsta/article/view/61/54. 